\title{
INVESTIGATING THE TOURISM EXPERIENCE OF THAI COOKING CLASSES: AN APPLICATION OF LARSEN'S THREE-STAGE MODEL
}

\author{
WANTANEE SUNTIKUL, ${ }^{*}$ ELIZABETH AGYEIWAAH, $†$ WEI-JUE HUANG, ${ }^{*}$ \\ AND STEPHEN PRATT: \\ *School of Hotel and Tourism Management, The Hong Kong Polytechnic University, \\ Kowloon, Hong Kong \\ $\dagger$ Faculty of Hospitality and Tourism Management, Macau University of Science and Technology, \\ Taipa, Macau SAR \\ $\ddagger$ School of Tourism \& Hospitality Management, The University of the South Pacific, Suva, Fiji
}

\begin{abstract}
Cooking classes have emerged as popular activities for international tourists seeking to learn and participate in Thai culinary culture. Applying Larsen's psychological three-stage model for understanding the tourism experience, this study identifies motivational and experiential factors of tourists' participation in cooking classes, and their subsequent behavioral intentions. Drawing on functional motivational theory and Pine and Gilmore's experience economy concept, a quantitative instrument is developed to survey 300 tourist participants in cooking classes in Chiang Mai, Thailand. Results suggest that the top-most motivational factor for participation in cooking classes is socioutilitarian needs - a combination of social and utilitarian items, whereas the top-most experiential factor is "Ent-escapist"-a combination of Pine and Gilmore's entertainment and escapist realms. The results indicate that both the motivational and the experiential facets of cooking clases are influenced by a combination of factors. These findings offer implications for the marketing of cooking class products by destination management organizations.
\end{abstract}

\section{Key words: Experience economy; Motivation; Cooking classes; Culinary tourism; Thailand}

Introduction

This study addresses an underdeveloped aspect of research into the food tourism experience: activities centered around tourists as food producers, not merely consumers. It investigates three facets of this experience: motivation to participate, experience during participation, and behavioral intentions after the experience.

Culinary tourism can be defined as "foodmotivated travel that occurs in places not typically part of one's everyday encounters" (de la Barre 
\& Brouder, 2016, p. 209) and "visitation . . . for which food tasting and/or experiencing the attributes of specialist food production region are the primary motivating factor" (Hall \& Sharples, 2003, p. 10). Culinary tourism is manifested in new tourism products such as food tours (Ko, Kang, Kang, \& Lee, 2018), food festivals (H.-C. Wu, Wong, \& Cheng, 2014), cooking classes (Spence \& Van Teijlingen, 2005), farm weekends and culinary trails (Long, 2013).

Cooking classes are emerging products in culinary tourism that allow tourists to participate in a destination's unique culture, which may appeal to different tourist types. Plog (2002) distinguished between "allocentric" tourists who seek adventure and new experiences and "psychocentric" tourists who prefer familiarity and comfort. Mitchell and Hall's (2003) typology of food tourist behavior identified four types of food tourists, and "cook schools" was one of the activities that separate the "neophiles/allocentrics" (i.e., people with high interest/involvement in wine and cuisine tourism) from the "neophobes/psychocentrics" (i.e., people with low interest/involvement) (p. 78-79).

Changes in social values and travel culture have produced a new generation of tourists (Krippendorf, 1986). While traditional mass tourists are often criticized for only being interested in sun/sand/sea, these "new tourists" seek new and individualized experiences (Burns \& Holden, 1995). They think, feel, care about the community, take responsibility for their actions, and are ready to learn (Krippendorf, 1986). With the rise of the experience economy, new tourists have further evolved-from passive learners and sightseers to active consumers seeking interactive, memorable, emotionally satisfying experiences (Andersson, 2007; Mehmetoglu \& Engen, 2011). Compared to other types of culinary activities, such as dining at mainstream restaurants at the destination, cooking classes may be preferred by these active, experience-seeking travelers.

A diversity of perspectives and models of tourist experience have emerged, such that there is little consensus regarding the essence of tourism experiences and the mechanisms by which they are constructed (Ritchie \& Hudson, 2009; Volo, 2013). Larsen (2007) proposes that the tourist experience consists of three stages: the pretrip planning process, activities during the trip, and tourists' posttrip recollection of these events. All three elements must be examined to achieve a comprehensive understanding of tourist psychology.

Food tourism experiences have received less attention than other forms of special interest tourism (Horng \& Tsai, 2012; Quan \& Wang, 2004; Tsai \& Wang, 2017). While some studies examine food as an attraction for tourism (e.g., Kivela \& Crotts, 2006; Promsivapallop \& Kannaovakun, 2019), most focus on food consumption, rather than food production, perhaps because food production-related activities may be seen as involving "labor" and contradicting the notion of "holiday." Nevertheless, as tourists pursue more unique and memorable experiences, culinary tourism has evolved beyond eating to encompass more interactive, participatory, and activitybased experiences (Ko et al., 2018). Numerous production-related activities have emerged, such as cooking and baking classes, local market tours, fruit picking, cheese making, and beer crafting. Sharples (2003) described tourists attending cooking schools as "food explorers" in search of "a food learning experience," desiring "real" and "authentic" food, to see where the food came from, what it's made of, and how it's made. These activities merit investigation as a category in their own right.

This study seeks to understand the factors that contribute to the attractiveness of this activitybased attraction to tourists, and the dissemination of messages communicating this attractiveness. This article investigates the cooking school experience from all three of Larsen's (2007) perspectives: the preactivity mechanisms that motivate tourists to join these activities, the factors that contribute to tourists' perceiving the experiences gained in these activities as valuable, and the ways in which positively perceived experiences influence intended future behavior regarding the food and culinary culture of the destination, as well as influencing the behavior of others. The research has three primary objectives. Firstly, the research identifies motivational factors underlying tourists' participation in cooking classes; secondly, it identifies the experiential value dimensions of these cooking classes for participants that constitute their perceived attractiveness; and thirdly, it assesses the degree to which experiential value dimensions impact future behavioral intentions. 
The study presented in this article was conducted in Chiang Mai, a principal city of northern Thailand, $700 \mathrm{~km}$ from Bangkok. Chiang Mai is endowed with stunning natural beauty, winning it the accolade "The Rose of the North." Its renowned traditions attract many tourists. Chiang Mai represents a prominent culinary hub for tourists (Agyeiwaah, Otoo, Suntikul, \& Huang, 2019; Soonsap, 2018) with many cooking schools such as Thai Kitchen Cookery Centre, Thai Akha Cooking School, Benny's Home Cooking Chiang Mai, Zabb E Lee Thai Cooking School, and Thai Orchid Cookery School (TripAdvisor, 2018), making Chiang Mai an ideal context for the examination of the cooking class experience.

\section{Literature Review}

\section{Culinary Tourism}

Food tourism generally implies participation in food-related activities during a trip (Hall \& Mitchell, 2001; Tsai \& Wang, 2017). In distinction to other food tourism terms like cuisine tourism, which emphasizes cooking and preparation styles, and gastronomy tourism, which focuses mainly on the consumption of food and drink, culinary tourism encompasses a more comprehensive range of food-related activities and elements, including the practice of various food preparation styles and the contexts in which food is obtained, prepared, and eaten (Horng \& Tsai, 2012; S. L. J. Smith \& Xiao, 2008), making it a facet of cultural tourism (Richards, 2018). Culinary tourism is exemplified by cooking classes where tourists are given the opportunity to not only engage in cooking and consumption of food but also to experience associated cultural aspects of the destination (Bell, 2015) qualifying it as a third-generation holistic gastronomic experience (Richards, 2015).

Specific studies on cooking classes remain scant. Among these, S. Smith and Costello (2009) identified 27 attributes of a culinary event using Importance Performance Analysis, in which three attributes are found to predict overall performance. Harrington, Ottenbacher, and LöWenhagen (2015) adopted an expectancy-based approach to test the effect of culinary and hospitality attributes on decisions to return to a culinary destination. Kim,
Suh, and Eves (2010) found that food neophobic traits have a negative effect on satisfaction and loyalty among visitors attending food events and festivals. Ko et al. (2018) segmented an emerging Korean food tour market into authenticity seekers, knowledge seekers, guidance seekers, and utmost experience seekers. As cooking schools emerge as experiential attractions for tourists and economic activities for locals (Bell, 2015), the need for a comprehensive examination of the tricomponent attitudes of participants becomes crucial.

\section{The Tricomponent Attitude Model}

In addition to Larsen's (2007) psychological three-stage model, the current study is underpinned by the tricomponent attitude model (Yuan, Morrison, Cai, \& Linton, 2008), which applies three factors to explain consumers' favorable and unfavorable reactions to products or services. These factors include a cognitive component, affective component and behavioral component (Mengli, 2005).

The cognitive component encompasses knowledge and information from various sources, which may stimulate desire to consume or purchase the product. The affective component relates to emotional states or feelings about the specific product, which may explain positive or negative experiences of the consumer. The behavioral component relates to the tendency of the consumer to engage in a specific action (Holbrook \& Hirschman, 1982; Yuan et al., 2008). Motivations, experiences, and behavioral intentions are all important constructs for understanding culinary tourist behavior (Agyeiwaah et al., 2019; Y. G. Kim \& Eves, 2012), yet culinary studies usually examine these factors separately (e.g., Ignatov \& Smith, 2006; Y. G. Kim \& Eves, 2012; Tikkanen, 2007). This study addresses this deficiency by examining motivations (cognitive), experiences (affective), and behavioral intentions (conative) components in tandem.

\section{Tourist Motivations}

As a significant determinant of recreational behavior (Whang, Yong, \& Ko, 2016), motivation is defined as a set of forces that underlie individual behaviors(Gällstedt,2003).Motivation“occurswhen 
an individual wants to satisfy a need" (Goossens, 2000, p. 320). Motivation implies psychological/ biological needs and wants that direct individual behavior and activities (Dann, 1981; Pearce, 1982). Tourism motivation stimulates a quest to satisfy needs and desires by engaging in appropriate leisure activities (Tabassi \& Bakar, 2009). Effective tourism marketing depends on understanding consumer motivations (Fodness, 1994), substantiating research interest on why people travel (Parrinello, 1993)

Causal relationships have been identified between motivation, satisfaction, and destination loyalty (Yoon \& Uysal, 2005). Tourists build expectations based on both "push" motivations (factors in tourists' lived reality that motivate them to travel) and "pull" motivations (attributes of the destination that attract them to travel) (Crompton, 1979; Dann, 1981), and their satisfaction with the tourism experience involves comparing these expectations to their actual experiences (Correia, Kozak, \& Ferradeira, 2013).

Motivating factors can be identified for specific behaviors, such as "excitement" and "escape from routine" as motivations for tourists to try local food and beverages when traveling (Ohanian, 1990). Tourist motivations need to be understood in terms of both the nationality of the tourist and the culture of the destination (Kozak, 2002). Differences in tourists' source cultures (such as the distinction between individualist and collectivist cultures) affect motivations (Fu, Cai, \& Lehto, 2017; C. Kim $\&$ Lee, 2000).

Functional motivation theory (Fodness, 1994) understands motivation in terms of the envisioned ends that motivate conscious actions. In this vein, Gnoth (1997) identifies five key psychological functional roles of tourism activities that stimulate behavior: knowledge, value-expressive, utility, egodefensive and social-adjustive (Katz, 1960). The knowledge function describes an individual's quest to expand their understanding and knowledge of the world, the utilitarian function denotes individuals' efforts to simplify decision-making processes, the social-adjustive function refers to people's endeavors to establish or maintain social relationships with others. The value-expressive function is the function by which an individual expresses their self-identity to others. Finally, the ego-defensive function describes one's actions (or inactions) to defend one's self-esteem (Fodness, 1994).

Motivation can be understood in terms of relationships between tourists' personalities and the types of activities they choose (Cohen, 1972). Goeldner and Ritchie (2012) suggested four distinctions to articulate motivations based on individual preferences: familiarity/novelty, order/disorder, activity/ relaxation and dependence/autonomy.

Motivations must be understood in relation to needs (Witt \& Wright, 1992). The "travel career ladder" establishes a hierarchy of needs that motivate tourist behavior, with relaxation needs as the lowest of five levels and fulfillment needs as the highest (Pearce, 1988). Needs hierarchy approaches to understanding motivation can also be applied to particular destinations or activities, for instance with needs related to friendship and contact with people having been found to be primary motivators in the context of tourism (Ross, 1993). The level of motivation for a given tourist can also be affected by travel experience (Pearce \& Lee, 2005).

It is important that tourism stakeholders at a destination recognize what motivates tourists to come to that destination, in order to appeal to them in an articulate manner. Attractive destinations tend to have multiple attributes that motivate tourists to visit (Farmaki, 2012). Motivation and behavioral indicators have been found to affect overnight stays (Serra, Correia, \& Rodrigues, 2014). Marked differences in destination region of choice have been discovered, depending on motivation for travel (Bansal \& Eiselt, 2004).

The food tourism literature is replete with studies examining motivations of culinary tourists (e.g., Antón, Camarero \& Laguna-García, 2017; Y. G. Kim \& Eves, 2012; Sánchez-Cañizares \& López-Guzmán, 2012). Enright and Newton (2004) found that tourists rank gastronomy as the second most attractive aspect of visitation (28\%) after safety, above nightlife, visual appeal, and climate. Similarly, SánchezCañizares and López-Guzmán (2012) examined motivations of culinary tourists to Cordoba, Spain and found that cuisine was the second most important motivation. Y. G. Kim and Eves (2012) found five motivational dimensions for the consumption of local food, namely cultural experience, interpersonal relations, excitement, sensory appeal, and health concerns. Given the heterogeneous nature of 
food tourists (Sánchez-Cañizares \& López-Guzmán, 2012), motivations for participating in a different food activity such as cooking classes are likely to differ and further study is warranted.

\section{Tourism in the Experience Economy}

Pine and Gilmore (1999) coined the term "experience economy" to express their view that the perceived value of the experience afforded by goods, services, and activities that above all determines economic value for consumers. They develop a model based on four different experience "realms"Entertainment, Escapist, Education, and Estheticthat encompass the range of modalities that experiences can take.

Experiences are conceived as being simultaneously produced and consumed by tourists. The perceived value of the experience depends on the state of mind of the consumer at the time of consumption, which in turn depends on the level of satisfaction of their basic, societal and intellectual needs (Andersson, 2007). The four experience dimensions can affect perceived well-being (Hwang \& Lyu, 2015), and different dimensions predominate in different situations. Mehmetoglu and Engen (2011) noted the prevalence of the Escapist and Esthetic dimensions in a Norwegian music festival, whereas Education and Esthetic dimensions are more important in the experience value of a museum in the same region. Studies find the Escapist dimension to be prevalent in shopping-centered experiences (Mathwick, Malhotra, \& Rigdon, 2001), and identified the Esthetic realm as predominant in Macao's Historic Center (Suntikul \& Jachna, 2016).

Experience is closely related to perceived value and satisfaction (H. J. Song, Lee, Park, Hwang, \& Reisinger, 2015). Contexts that offer opportunities for immersion in a local culture in a multifaceted way, such as temple stays in Korea (H. J. Song et al., 2015), are highly valued for their experience value. The experience economy concept relates closely to place attachment (Loureiro, 2014), and successful experiences can influence more vivid memories of a place, and encourage destination loyalty (Manthiou, Lee, Tang, \& Chiang, 2014). This approach has been used to study not just the experience onsite but also the anticipated experience of a destination (Osmond, Chen, \& Pearce, 2015).
The experience economy approach in tourism relies on place-bound elements of a destination (Lorentzen \& Hansen, 2009) and serves as a basis for understanding what motivates purchase decisions and loyalty (Morgan, Elbe, \& de Esteban Curiel, 2009). It has also been specifically adapted to domains such as wine tourism (Quadri-Felitti \& Fiore, 2012) and other culinary tourism contexts (Sidali, Kastenholz, \& Bianchi, 2015).

The range of experiences in culinary tourism is wide, consisting of consumption-oriented (Jolliffe, 2003), observational (Mitchell \& Hall, 2003), and participatory (Walter, 2017) facets. Sims (2009) argued that local cuisine "has the potential to enhance the visitor experience by connecting consumers to the region and its perceived culture and heritage" (p. 321). In this way, visitors become increasingly aware and emotionally connected to the destination, which can yield loyalty (Mason \& Paggiaro, 2012). Ko et al. (2018) identified four clusters of food tourists, namely "authenticity seekers," "knowledge seekers," "guidance seekers," and "experience seekers" and compare them across seven food tour service factors. The authors found experience seekers are more concerned with product flexibility including dietary restrictions, personal preferences, and flexible starting times, than other tourists. While experiences differ among different culinary tourists, little has been published about such experiences within cooking classes (Long, 2013). Hence, the current study argues for further examination of the cooking class experience based on Pine and Gilmore's concept of the experience economy.

\section{Behavioral Intentions of Tourists}

Behavioral intention is a way of understanding the actions that an individual plans to perform (Oliver $\&$ Swan, 1989). Behavioral intention has a direct effect on behavior, and can be attributed to factors including evaluative beliefs, social factors, and contextual factors (Moutinho, 1987). Past behavior is a modifying factor in predicting a given person's future behavior (Ouellette \& Wood, 1998).

Tourists' experiences have been found to influence future intention to visit or recommend a destination (Cevdet Altunel \& Erkurt, 2015; Huang \& Hsu, 2009). Studies have addressed particular areas 
within which behavioral choices are made by tourists, such as Chinese college students' intentions to travel to Japan (Park, Hsieh, \& Lee, 2017) and tourists' intention to travel overseas for sports tourism (Yu, 2010). Mason and Paggiaro (2012) found that the relationship between "festivalscapes" (the experiential landscapes generated by the various factors and elements that constitute a festival) and visitors' future behavior is mediated by satisfaction. Within the cooking class context where experiences are varied (Long, 2013), behavioral intentions may differ for different experiences and further studies into cooking classes in the context of tourism is pertinent.

\section{Methods}

\section{Instrument Design and Measures}

The study is quantitative in nature and relied on primary data collection using a questionnaire (Creswell, 2009), due to the flexibility this instrument offers both the respondents and the researcher in terms of convenience and cost of administration (Bryman, 2012). The questionnaire was designed in sections, according to the study's three broad objectives, with additional questions on respondents' sociodemographic characteristics.

To ensure reliability and validity, all measures used in the questionnaire were based on existing literature and the reliability of these items is assessed by a Cronbach's alpha reliability test. The research question on respondents' motivation was based on functional motivation theory (Fodness, 1994; Katz, 1960). Fodness (1994) provided an example that his knowledge function relates to statements like "travel gives you a better understanding of current events." Applying this to the current study, statements like "I would like to learn something new" and "I would like to know more about Thai cuisine" were used. Other measures used in this study applied similar statements suggested by Fodness (1994) and Katz (1960). Overall, 11 items were developed to measure respondents' motivation. This was further explored using factor analysis to identify underlying dimensions. These questions assess motivation, the psychological drivers to a tourist experience in Larsen's (2007) three-stage approach.
The construct of experiences used in this study was based on the Pine and Gilmore's (1999) Experience Economy theory. Examples of questions used to measure the Entertainment realm included "I found this cooking class to be entertaining" and "I had a lot of fun in this class." Seventeen statements were used, with four deleted due to low factor loadings, leaving 13 reliable items for statistical analysis. This section captured perceptions of the tourism experience, Larsen's (2007) second step in the psychology of the tourist experience.

Finally, respondents' future behavioral intentions were captured, the final step in Larsen's (2007) approach. Measures used for future intentions regarding Thai food and culinary culture were based on studies by Lee, Lee, and Choi (2011) and H. Song, van der Veen, Li, and Chen (2012), who defined future intentions as repetition/repurchase intentions and recommendation of a product after the encounter. Five items were used to measure future intentions on a 5-point Likert scale to assess respondents' level of agreement with the statements, and an option for "not applicable": strongly disagree $=1$, disagree $=2$, neither agree nor disagree $=3$, agree $=4$, and strongly agree $=5$. The researchers pretested the survey instrument on a small group of undergraduate tourism and hospitality students who have visited Thailand and were familiar with cooking classes. Several small changes were made to wording to improve comprehension.

\section{Data Collection Process}

Data collection for this research was conducted in Chiang Mai, a popular tourist destination in the North of Thailand that offers a range of cooking schools (Tourism Authority of Thailand, 2013). Cooking classes in Chiang Mai are typically halfday (4 hr) or full-day (6-7 hr) packages. While the menus may vary, dishes are generally divided into six categories (Stir-fried, Appetizer, Soup, Curry Paste, Curry, and Dessert) and participants can choose to learn three to five dishes depending on their class duration.

According to the travel website TripAdvisor, cooking classes are among the "must do" activities in Chiang Mai (TripAdvisor, 2018), making it an appropriate study site for examining cooking classes. Through TripAdvisor listings, the 
researchers identified cooking schools and sought permission to approach their students to conduct the research. Prior to data collection, the instrument was pilot tested on a smaller sample of cooking school participants, a screening question was employed to identify international tourists, given the need for study on international tourists' participation in cooking classes in Asia (Cohen \& Avieli, 2004). Of the 20 cooking schools in Chiang Mai at the time of the data collection, 15 allowed the researchers to approach their customers. Data collection took place in May 2016. As all respondents were international tourists who could speak English, the questionnaire was designed and administered in English. The questionnaire was conducted by field research assistants trained to administer the instruments, each assigned to a particular school. Assistants conducted questionnaires at each school until all willing respondents within the school had been surveyed, at which point the assistant proceeded to the next assigned school. Respondents were selected using convenience sampling, yielding 300 usable questionnaires for analysis, giving a maximum sampling error of $\pm 5.66 \%$, deemed appropriate for analysis. Covering 15 out of 20 cooking schools with a sample size of 300 contributes to the sample being representative of the larger population. For each respondent, the survey took between 15 and $20 \mathrm{~min}$. Social desirability bias was reduced by assuring research subjects of anonymity and confidentiality at the introductory part of the questionnaire (Larson, 2019). This method can encourage respondents to truthfully answer questions without considering how the answers would be viewed by others.

\section{Data Analysis}

When data collection was complete, the resulting dataset was cleaned and data inputted into SPSS software to facilitate analysis. Principal component factor analysis was used to identify factors that explain motivational and experiential values of participation in cooking classes among tourists. Additional analysis included $t$ test and one-way analysis of variance designed to detect significant differences in different sociodemographic segments across identified motivational and experiential factors. Regression analysis was conducted to assess the impact of experience factors on future intentions based on Namkung and Jang's (2007) argument that quality food experiences have a significant influence on behavioral intentions, with Y. G. Kim et al. (2010) highlighting the connection between experiential components like satisfaction and loyalty. The authors chose SPSS regression over SmartPLS due to the assumption of normality that is pertinent to the estimation of $p$ values but is overlooked by the latter software (Sosik, Kahai, $\&$ Piovoso, 2009). The above analyses address the three main objectives of the study.

\section{Findings}

\section{Sociodemographics}

More than half $(53.3 \%)$ of the respondents were female, corresponding to the general prevalence of this gender in participatory food activities (Björk \& Kauppinen-Räisänen, 2016). About 59\% of respondents were aged between 20 and 39, and most were well-educated, with either a vocational $(28.0 \%)$ or bachelor's degree (45.3\%) level of education. The predominant age group of the current study was different from other previous studies (e.g., Björk \& Kauppinen-Räisänen, 2016). The largest segment $(40.0 \%)$ of the participants was singles who could be expected to have more individual discretionary time to travel independently than their cohabiting or married counterparts. The majority of respondents were first-time visitors to Thailand $(62.7 \%)$. Table 1 gives an overview of the demographic profile of the sample.

\section{Participants' Motivations}

In this section, cooking class participants' motivations were assessed to understand the factors in the preactivity phase that influence decisions to participate in the activity. As shown in Table 2, two main functional roles of cooking classes were identified. Factor analysis (principal axis factoring) revealed two main dimensions that can be grouped into Factor One: Socioutilitarian and Factor Two: Knowledge and Value-expressive needs.

The indices from the factor analysis suggest that the topmost declared motivations for joining cooking classes among the sample were social and 
Table 1

Sociodemographic Profile of Respondents $(N=300)$

\begin{tabular}{lc}
\hline Variable & Frequency (\%) \\
\hline Gender & \\
Male & $140(46.7 \%)$ \\
Female & $160(53.3 \%)$ \\
Age & \\
15-19 & $35(11.7 \%)$ \\
$20-29$ & $102(34.0 \%)$ \\
$30-39$ & $76(25.2 \%)$ \\
$40-49$ & $53(17.7 \%)$ \\
$50-59$ & $20(6.7 \%)$ \\
60 or above & $14(4.7 \%)$ \\
Educational level & \\
Below high school & $12(4.0 \%)$ \\
High school & $45(15.0 \%)$ \\
Vocational or associate degree & $84(28.0 \%)$ \\
Bachelor's degree & $136(45.3 \%)$ \\
Masters or doctorate & $23(7.7 \%)$ \\
Marital status & \\
Single & $122(40.7 \%)$ \\
Cohabiting & $81(27.0 \%)$ \\
Married & $90(30.0 \%)$ \\
Divorced & $7(2.3 \%)$ \\
How many times have you been to & \\
Thailand (including this visit)? & \\
First time & $188(62.7 \%)$ \\
Two times & $67(22.3 \%)$ \\
Three times & $28(9.4 \%)$ \\
Four times & $9(3.0 \%)$ \\
Five or more times & $8(2.6 \%)$ \\
\hline
\end{tabular}

utilitarian needs, accounting for $24.1 \%$ of the variance explained (Eigenvalue $=4.31 ; \alpha=0.81$ ). In terms of social needs, cooking classes are activities that enable participants to interact with local people and their culture, while providing a channel for engaging in experiential social activities at the destination. Previous studies by Y. G. Kim et al. (2010) found the experiential value of food activities during travel to be among the most important motivations for tourists. Earlier studies on tourism trends in the Asia Pacific Region confirmed the rise in participatory rather than passive tourism activities (Tolkach, Chon, \& Xiao, 2016). Such findings are corroborated by the current study. Utilitarian needs were found in this study to occur side-by-side with social needs, which revealed that participants are motivated to join these activities as means to the end of fulfilling a "must do" tourism itinerary.

Factor Two consisted of knowledge and valueexpressive needs, accounting for $22.7 \%$ of the variance explained (Eigenvalue $=1.83 ; \alpha=0.82$ ) . Cooking class participants are keen to know more about the destination. By engaging in cooking classes, participants get opportunities to further understand the local culture (specifically, the culinary culture) of the destination. This functional role of leisure is important for visitors to broaden their horizons of knowledge about the world (Waller \& Lea, 1999). Y. G. Kim et al. (2010) found that knowledge seeking through food experiences is an important motivation that enables tourists to understand local cultures. Getz (2000) argued that food tourism participation provides tourists with important cultural information on table manners

Table 2

Motivating Factors of Engaging in Cooking Schools $(\mathrm{N}=300)$

\begin{tabular}{lrr}
\hline Extracted Dimension/Statement & Factor Loading & Mean $(S D)$ \\
\hline Factor 1: Socioutilitarian needs (Eigenvalue = 4.31; variance explained 24.1\%; & Cronbach's alpha = 0.81) \\
I wanted to get good photographs of what I learned from this cooking class. & 0.66 & $3.44(1.108)$ \\
I joined because a friend or family member recommended me to join. & 0.60 & $3.33(1.107)$ \\
This activity allows me to interact with local people and also with tourists. & 0.58 & $3.58(0.974)$ \\
I didn't have anything much to do. & 0.57 & $2.94(1.284)$ \\
I wanted to experience authentic Thai culture. & 0.55 & $3.56(1.121)$ \\
I wanted to experience the most popular "must do" activity. & 0.52 & $3.50(0.979)$ \\
I was looking for a unique experience. & 0.52 & $3.44(1.185)$ \\
Cooking classes are promoted as a "must do" activity in Chiang Mai. & $3.62(0.979)$ \\
Factor 2: Knowledge and value expressive needs (Eigenvalue=1.83; variance explained 22.7\%; Cronbach's \\
alpha=0.82) \\
I would like to learn something new. \\
I would like to join an enjoyable activity. \\
I would like to know more about Thai cuisine. & 0.83 & $3.90(0.881)$ \\
\hline
\end{tabular}

Note. Kaiser-Meyer-Olkin (KMO) measure of sampling adequacy $=0.822$; Bartlett's test of sphericity: approx. $\chi^{2}(55)=1181.334, p=0.000$. 
in a destination. In combination with knowledge needs were value-expressive needs. For most tourist participants in cooking classes, experiencing authentic food culture is of great importance. As Y. G. Kim et al. (2010) argued, most tourists feel that even though they may be able to get many kinds of ethnic food in their home country, the taste is usually different than the version prepared in the country of the cuisine's origin, providing motivation to participate in cooking classes. This empirical finding is indicative of how tourists participating in cooking classes value the perception of authentic rather than staged experiences at the destination.

Cooking class participation is motivated by different types of psychological functions (needs) that participants expect to satisfy through these activities (Fodness, 1994). Motivation to participate in cooking classes is strongly influenced by the social and utilitarian functions of the product, supported by knowledge and value-expressive functions. By applying the functional theory of motivation, the underlying factors behind participants' decision making are revealed (Gnoth, 1997). The findings of this subsection are relevant for marketing purposes. Indeed, Fodness (1994) argued that effective marketing is impossible without in-depth understanding of consumer motivation since it reveals the stimulating force behind tourist behavior.

\section{Participants' Experiences}

Each of Pine and Gilmore's (1999) four experience realms correspond to a specific aspect of the ways in which humans experience a phenomenon (Table 3): Entertainment represents sensing, Educational represents learning, Escapist represents doing, and Esthetic represents being there (Petkus Jr., 2004). The degree of convergence of these dimensions in a multifaceted experience indicates how rich the experience is to the consumer (Williams, 2006).

Factor analysis (principal axis factoring) revealed two main factors underlying respondents' cooking class experiences. The factor loadings of all four realms were quite high (ranging from 0.81 to 0.51 , with the exception of one). The first factor is a combination of Entertainment and Escapist items, named "Ent-escapist." This factor accounts for $27.7 \%$ of the variance explained (Eigenvalue $=3.61 ; \alpha=0.90)$ and is the dominant factor underlying respondents' participation in cooking classes. Previous studies by Y. G. Kim et al. (2010)

Table 3

Experiential Factors of Cooking Class

\begin{tabular}{|c|c|c|}
\hline Extracted Dimension/Statements & $\begin{array}{l}\text { Factor } \\
\text { Loading }\end{array}$ & Mean $(S D)$ \\
\hline \multicolumn{3}{|l|}{ Factor 1: Ent-escapism (Eigenvalue $=3.61 ;$ variance explained $27.7 \% ;$ Cronbach's alpha $=0.90)$} \\
\hline I found this cooking class to be entertaining. & 0.81 & $4.02(0.838)$ \\
\hline I had a lot of fun in this class. & 0.77 & $3.85(0.878)$ \\
\hline This cooking class gave me a feeling of the unique local environment. & 0.75 & $3.87(0.828)$ \\
\hline $\begin{array}{l}\text { I felt I was able to immerse myself more meaningfully in Thai culture through this cook- } \\
\text { ing class. }\end{array}$ & 0.62 & $3.80(0.894)$ \\
\hline $\begin{array}{l}\text { I feel that through this cooking class I was able to "participate" in Thai food culture, not } \\
\text { just consume. }\end{array}$ & 0.59 & $3.93(0.827)$ \\
\hline Participating in this cooking class was a pleasure to the senses. & 0.54 & $4.00(0.887)$ \\
\hline I learned many things from this cooking class that I didn't know before. & 0.51 & $3.92(0.872)$ \\
\hline \multicolumn{3}{|l|}{ Factor 2: Est-education $($ Eigenvalue $=2.75 ;$ variance explained $21.2 \% ;$ Cronbach's alpha $=0.77)$} \\
\hline This class provided me with an education in Thai culture. & 0.64 & $3.88(0.913)$ \\
\hline This class has helped me to appreciate the beauty of Thai food. & 0.59 & $3.93(0.822)$ \\
\hline This cooking class was an unexpected discovery for me. & 0.58 & $3.80(0.893)$ \\
\hline The cooking instructor introduced not only cooking, but also Thai culture. & 0.55 & $3.88(0.843)$ \\
\hline Cooking classes are promoted as a must-do activity for visitors to Chiang Mai. & 0.54 & $3.73(0.884)$ \\
\hline I personally liked this cooking class, but probably not everyone would appreciate it. & 0.32 & $3.64(0.980)$ \\
\hline
\end{tabular}

Note. Kaiser-Meyer-Olkin (KMO) measure of sampling adequacy $=0.923$; Bartlett's test of sphericity: approx. $\chi^{2}(78)=1783.462$, $p=0.000$. 
attested that the freedom to escape and be entertained are important components for participants in food tourism activities. In their study, most participants explained that food tourism allows them to experience different things than in their day-to-day lives.

The second identified factor was a combination of Esthetic and Educational realms captioned "Esteducation." This second factor suggests that the Esthetic and Educational dimensions of cooking classes play a key role in providing participants with opportunities to learn more about Thai culture and to appreciate the beauty of Thai food. Such learning and sensory experiences through food tourism have been demonstrated as important in the extant literature. Y. G. Kim et al. (2010) found the Esthetic (visual image) attributes of the food to be very influential in tourists' destination choices. Björk and Kauppinen-Räisänen (2016) further argued that culinary experiences provide multidimensional experiences, embracing varied tourism activities. This was reaffirmed by the current study.

The final element of the findings analyzed intentions that prefigure postactivity behavior of cooking class participants. Future intentions represent an important influencer of postexperience behavior, closely related to loyalty, and can thus have a significant impact on revenue of tourism providers (Lee et al., 2011). Higher customer retention has a positive effect on profitability (Zeithaml, 1988). For that reason, exploring the future intentions of participants in cooking classes was of importance to this study.

Table 4 shows that all items pertaining to future intentions were ranked highly, with a relatively narrow range of means from 3.76 to 3.92 out of 5. Cooking class participants were keen to continue the cooking practices learned in the classes, recommend cooking classes to others, and to visit in the future. They were in high agreement that they will able to remember what they have learned during the experience. Memorability in this case may be supported by the participatory nature of the cooking classes that relies on active involvement of the tourists in the production of the experience rather than passive consumption, supporting Manthiou et al.'s (2014) assertion that strong experiences can engender vivid memories and destination loyalty.

Moreover, there was a desire among respondents to share their cooking class experiences with friends and relatives, potentially drawing other prospective visitors to the destination and the cooking classes. All respondents were also keen to recommend cooking classes to others, which contributes to knowledge and discussion of the destination and the activity in tourism source markets, potentially contributing to reputation and arrivals. The literature attests that positive future intentions have a significant impact on the revenue of destinations since they have the ability to attract people to destinations through word of mouth (Lee et al., 2011; H. Song et al., 2012). Significantly, respondents were motivated to visit Thailand again, indicating that positive experiences can encourage repeat visits. Respondents would also like to participate in further cooking classes. All of these findings point to intentions towards increased and continued engagement with Thai culinary culture. This makes it critical to examine how such future intentions are influenced by on-site experiential factors.

OLS regression analysis of the influence of experience on future intentions as argued in the literature was conducted to understand how the identified experiential factors can translate into future actions. The test indices indicated significant influence of both factors identified in this study:

Table 4

Future Intentions (Cronbach's $\alpha=0.823$ )

\begin{tabular}{lc}
\hline Items & Mean (SD) \\
\hline I will remember this cooking experience long after leaving Thailand. & $3.91(0.902)$ \\
I will cook the Thai dishes I learnt in this cooking class for my friends and relatives & $3.92(0.845)$ \\
I would personally recommend a cooking class as a must do activity in Chiang Mai. & $3.89(0.877)$ \\
After taking this cooking class, I am likely to visit Thai restaurants in my country more often. & $3.78(0.905)$ \\
I would like to join more cooking classes in Thailand if I could. & $3.76(0.863)$ \\
\hline
\end{tabular}


Table 5

Influence of Experience on Future Intentions

\begin{tabular}{ll}
\hline Constructs/Variables & Beta Coefficients \\
\hline (Constant) & $3.84^{* * *}(160.190)$ \\
Ent-escapism & $0.36^{* * *}(13.02)$ \\
Est-education & $0.45^{* * *}(15.06)$ \\
$R^{2}$ & 0.65 \\
Adjusted $R^{2}$ & 0.64 \\
Durbin-Watson (DW) & 1.87 \\
$F$ & 257.95 \\
Tolerance & 0.95 \\
VIF & 1.05 \\
\hline
\end{tabular}

Note. Future intention is the dependent variable. The values in parentheses are $t$ statistics.

$* * * p<0.001$

Ent-escapist $(\beta=0.36 ; t$ value $=13.0)$ and Esteducation $(\beta=0.45 ; t$ value $=15.1)$. Further diagnostic testing revealed the results to be valid and reliable (Table 5). The results substantiate the argument in the literature on the link between positive food experiences and future behavior (Y. G. Kim et al., 2010; Namkung \& Jang, 2007).

\section{Discussion and Conclusions}

Applying Larsen's three-stage model, this article explores the psychological dimension of tourists' paths through the preactivity, during activity, and postactivity phases of their participation in a particular tourism product: cooking classes in Chiang Mai, Thailand. Tourists' participation in these classes is motivated primarily by social and utilitarian functions, and secondarily by knowledge and value-expressive functions. The two-dimensional factors identified for on-site experience of this tourist activity hit the "sweet spot" in providing highly valued experiences in all four of Pine and Gilmore's (1999) realms of experience: Entertainment, Education, Escapist, and Esthetic. Participants are likely to intend to engage in future behavior of different types, reaffirming their loyalty to the brand of Thai culinary culture, and to contribute to spreading positive associations with this brand.

This supports Pine and Gilmore's central claim that highly valued experiences are rewarded with loyalty to the brand, which in this case can be understood as the Thai national culinary brand, with respondents' feelings of loyalty to this brand being expressed in their intentions to recommend cooking classes to others, to continue to cook Thai food after they return home, and to patronize Thai restaurants in their home country.

Williams (2006) stated that "much tourism activity is of an Esthetic nature, with tourists immersing themselves in the experience, but with little active participation in the experience" (p. 488). The goal of experience-led planning and marketing should be to transcend such unidimensionality, and the findings of this study indicate that cooking classes in Chiang Mai already provide the rich experiential prerequisites for this.

In affirmation of this, Björk and KauppinenRäisänen (2016) have argued that travelers' food experiences are multidimensional, interactive, and worthy of the attention of tourism marketers. They have the potential to incorporate all four experience realms, leading to "sweet spot" experiences for participants akin to attractions like the Disney theme parks in their comprehensiveness. This convergence of all experience realms is an important competitive advantage for destination marketing organizations (DMOs). The convergence of all realms in cooking school activities in Chiang Mai mean that these are activities that could be marketed to a wider group of tourists including those particularly attuned to either one or more of the experiential realms.

Respondents' declared future intentions to recommend cooking classes to others is another important aspect in encouraging patronage of these activities (and, by extension, encouraging travel to Chiang Mai), as word of mouth is a potent factor in motivating such travel decisions (Lee et al., 2011; H. Song et al., 2012). In influencing behavioral intentions not just of the tourist him/herself, but also of others, recommendation of an activity from a trusted individual would boost the perceived "brand equity" (Horng \& Tsai, 2012) of the product in the narrow sense (the activity itself, in this case cooking classes), the medium scale (the destination, Chiang Mai), and in broad terms (the value of the national or cultural brand, the Thai culinary culture).

Electronic dissemination, through food blogs and the like, is a common and wide-reaching way in which such recommendations are spread through "electronic word of mouth," which has been shown to encourage people to try the unfamiliar in their 
tourism activities (M.-Y. Wu \& Pearce, 2014). Online social platforms can play multifaceted roles in taking advantage of opportunities revealed by this research. Respondents' high expressed desire to continue the cooking practices learned in the classes, recommend cooking classes to others, and to visit in the future can all be supported through such platforms. When hosted by a DMO or similar governmental tourism body, these platforms can perform various roles, including: providing access to a sanctioned and coherent base of information on Thai cooking culture; fostering a community of interest around Thai cooking; supporting discussions that sustain interest in Thai cuisine and repeat visits to Thailand among this group; giving the DMO a platform for marketing directly to this community; and providing a forum for exchange of information between those who have already participated in cooking classes and those who are considering participating, thereby closing the loop between the postvisit experience of one cohort of tourists and the previsit motivating phase of the next group.

This last function also plays on the revealed connection between social and utilitarian factors in the pretrip planning phase, providing a point of access to practical information for planning participation in a course while also drawing the potential tourist into social contact with others who have participated in cooking classes or who are interested in them.

The other pair of linked factors in the preplanning phase - the knowledge and value-expressive dimensions - imply that the knowledge obtained in these classes is valued as an expression of a connection with Thai culture, emphasizing the nature of cooking classes as elements of (intangible) cultural heritage tourism. This opens up the prospect for a range of cooking experiences to be integrated into cultural heritage packages, tours, and attractions to give another dimension to tourists' experience: learning to prepare dishes linked to a particular historical period, person, event or place as part of a holistic cocreative tourism experience.

For both Pine and Gilmore's (1999) experience economy concept and Gnoth's (1997) psychological functional roles of tourism activities, this research has demonstrated nuanced insights into a specific tourism context that can be articulated through pairings of attributes. For instance, the identified hybrid between the Esthetic and Education dimensions in the cooking school experience unites two experience realms considered as opposites in Pine and Gilmore's model (the former being passive and immersive, the latter active and absorptive) to describe the desire of new tourists for experiences in which they actively participate in learning local knowledge on how to create aesthetically pleasing experiences. Similar conclusions can be drawn for the identified hybrid of the Entertainment (passive/ absorptive) and Escapist (active/immersive) realms. Such findings could provide clues for the updating of these models to better accommodate the preferences and behavior of the new generation of engaged tourists.

This research has several limitations, which indicate opportunities for future research. Data were collected at a single point in time. Larsen's (2007) three-stage approach was used, assessing preactivity, during activity, and postactivity phases in the same survey instrument. An alternative way to measure preactivity, during activity, and postactivity phases would be to collect the cooking class participants' motivations before the cooking classes began, assessing the experience during the class, and assessing the postactivity future intentions after the class had ended. Although these methods might be difficult to implement in situ, it might provide a "cleaner" assessment of each of the measures. Future studies could consider this. Another limitation is that only a sample of cooking class schools was sampled. Fifteen out of 20 cooking class schools granted permission for us to undertake the research. While this is a healthy participation rate, it does not represent all cooking class schools. The schools that did not participant may have a different participant profile and responses across Larsen's three-stage tourist experience may be different from the sample. An alternative sampling methodology intercepting international tourists at major points of ingress and egress at Chiang Mai would provide a broader but less focused sample.

\section{References}

Agyeiwaah, E., Otoo, F. E., Suntikul, W., \& Huang, W.-J. (2019). Understanding culinary tourist motivation, experience, satisfaction, and loyalty using a structural 
approach. Journal of Travel \& Tourism Marketing, 36(3), 295-313.

Andersson, T. D. (2007). The tourist in the experience economy. Scandinavian Journal of Hospitality and Tourism, 7(1), 46-58. doi: 10.1080/15022250701224035

Antón, C., Camarero, C., \& Laguna-García, M. (2017). Towards a new approach of destination loyalty drivers: Satisfaction, visit intensity and tourist motivations. Current Issues in Tourism, 20(3), 238-260. doi: 10.1080/13683500.2014.936834

Bansal, H., \& Eiselt, H. A. (2004). Exploratory research of tourist motivations and planning. Tourism Management, 25(3), 387-396. doi: https://doi.org/10.1016/S02615177(03)00135-3

Bell, C. (2015). Tourists infiltrating authentic domestic space at Balinese home cooking schools. Tourist Studies, 15(1), 86-100. doi: 10.1177/1468797614550958

Björk, P., \& Kauppinen-Räisänen, H. (2016). Exploring the multi-dimensionality of travellers' culinary-gastronomic experiences. Current Issues in Tourism, 19(12), 1260 1280. doi: $10.1080 / 13683500.2013 .868412$

Bryman, A. (2012). Social research methods. New York, NY: Oxford University Press.

Burns, P. M., \& Holden, A. (1995). Tourism: A new perspective. Upper Saddle River, NJ: Prentice Hall.

Cevdet Altunel, M., \& Erkurt, B. (2015). Cultural tourism in Istanbul: The mediation effect of tourist experience and satisfaction on the relationship between involvement and recommendation intention. Journal of Destination Marketing \& Management, 4(4), 213-221. doi: https://doi. org/10.1016/j.jdmm.2015.06.003

Cohen, E. (1972). Toward a sociology of international tourism. Social Research, 39(1), 164-182.

Cohen, E., \& Avieli, N. (2004). Food in tourism: Attraction and impediment. Annals of Tourism Research, 31(4), 755-778.

Correia, A., Kozak, M., \& Ferradeira, J. (2013). From tourist motivations to tourist satisfaction. International Journal of Culture, Tourism and Hospitality Research, 7(4), 411424. doi: 10.1108/IJCTHR-05-2012-0022

Creswell, J. W. (2009). Mapping the field of mixed methods research. Journal of Mixed Methods Research, 3(2), 95-108. doi: 10.1177/1558689808330883

Crompton, J. L. (1979). Motivations for pleasure travel. Annals of Tourism Research, 6(4), 408-424.

Dann, G. M. S. (1981). Tourist motivation an appraisal. Annals of Tourism Research, 8(2), 187-219. doi: https:// doi.org/10.1016/0160-7383(81)90082-7

de la Barre, S., \& Brouder, P. (2016). Culinary tourism. In J. Jafari \& H. Xiao (Eds.), Encyclopedia of tourism (pp. 209-211). Cham, Switzerland: Springer.

Enright, M. J., \& Newton, J. (2004). Tourism destination competitiveness: A quantitative approach. Tourism Management, 25(6), 777-788. doi: https://doi.org/10.1016/j. tourman.2004.06.008

Farmaki, A. (2012). An exploration of tourist motivation in rural settings: The case of Troodos, Cyprus. Tourism Management Perspectives, 2-3, 72-78. doi: https://doi. org/10.1016/j.tmp.2012.03.007
Fodness, D. (1994). Measuring tourist motivation. Annals of Tourism Research, 21(3), 555-581. doi: https://doi. org/10.1016/0160-7383(94)90120-1

Fu, X., Cai, L., \& Lehto, X. (2017). Framing Chinese tourist motivations through the lenses of Confucianism. Journal of Travel \& Tourism Marketing, 34(2), 149-170. doi: 10.1080/10548408.2016.1141156

Gällstedt, M. (2003). Working conditions in projects: Perceptions of stress and motivation among project team members and project managers. International Journal of Project Management, 21(6), 449-455. doi: https://doi. org/10.1016/S0263-7863(02)00098-4

Getz, D. (2000). Explore wine tourism: Management, development and destinations. New York, NY: Cognizant Communication Corporation.

Gnoth, J. (1997). Tourism motivation and expectation formation. Annals of Tourism Research, 24(2), 283-304.

Goeldner, C. R., \& Ritchie, J. R. B. (2012). Tourism: Principles, practices, philosophies (12th ed.). Hoboken, NJ: John Wiley \& Sons.

Goossens, C. (2000). Tourism information and pleasure motivation. Annals of Tourism Research, 27(2), 301-321.

Hall, C. M., \& Mitchell, R. (2001). Wine and food tourism. In N. Douglas, N. Douglas, \& R. Derrett (Eds.), Special interest tourism: Context and cases (pp. 307-329). Brisbane, Australia: Wiley.

Hall, C. M., \& Sharples, L. (2003). The consumption of experiences or the experience of consumption? An introduction to the tourism of taste. In C. M. Hall, L. Sharples, R. Mitchell, N. Macionis, \& B. Cambourne (Eds.), Food tourism around the world (pp. 1-24). Oxford, UK: Routledge.

Harrington, R. J., Ottenbacher, M., \& LöWenhagen, N. (2015). Are culinary and hospitality service attributes key predictors of returning visits for culinary tourism locations? Journal of Gastronomy and Tourism, 1(1), 45-55.

Holbrook, M. B., \& Hirschman, E. C. (1982). The experiential aspects of consumption: Consumer fantasies, feelings, and fun. Journal of Consumer Research, 9(2), 132-140. doi: https://doi.org/10.1086/208906

Horng, J.-S., \& Tsai, C.-T. (2012). Exploring marketing strategies for culinary tourism in Hong Kong and Singapore. Asia Pacific Journal of Tourism Research, 17(3), 277-300

Huang, S., \& Hsu, C. H. C. (2009). Travel motivation: Linking theory to practice. International Journal of Culture, Tourism and Hospitality Research, 3(4), 287-295. doi: 10.1108/17506180910994505

Hwang, J., \& Lyu, S. O. (2015). The antecedents and consequences of well-being perception: An application of the experience economy to golf tournament tourists. Journal of Destination Marketing \& Management, 4(4), 248-257. doi: https://doi.org/10.1016/j.jdmm.2015.09.002

Ignatov, E., \& Smith, S. (2006). Segmenting Canadian culinary tourists. Current Issues in Tourism, 9(3), 235.

Jolliffe, L. (2003). The lure of tea: History, traditions and attractions. In C. M. Hall, L. Sharples, R. Mitchell, N. 
Macionis, \& B. Cambourne (Eds.), Food tourism around the world: Development, management and markets (pp. 121-136). Oxford, UK: Butterworth-Heinemann.

Katz, D. (1960). The functional approach to the study of attitudes. Public Opinion Quarterly, 24(2), 163-204. doi: $10.1086 / 266945$

Kim, C., \& Lee, S. (2000). Understanding the cultural differences in tourist motivation between Anglo-American and Japanese tourists. Journal of Travel \& Tourism Marketing, 9(1-2), 153-170. doi: 10.1300/J073v09n01 09

Kim, Y. G., \& Eves, A. (2012). Construction and validation of a scale to measure tourist motivation to consume local food. Tourism Management, 33(6), 1458-1467.

Kim, Y. G., Suh, B. W., \& Eves, A. (2010). The relationships between food-related personality traits, satisfaction, and loyalty among visitors attending food events and festivals. International Journal of Hospitality Management, 29(2), 216-226.

Kivela, J., \& Crotts, J. C. (2006). Tourism and gastronomy: Gastronomy's influence on how tourists experience a destination. Journal of Hospitality \& Tourism Research, 30(3), 354-377. doi: 10.1177/1096348006286797

Ko, S., Kang, S., Kang, H., \& Lee, M. J. (2018). An exploration of foreign tourists' perceptions of Korean food tour: A factor-cluster segmentation approach. Asia Pacific Journal of Tourism Research, 23(8), 833-846.

Kozak, M. (2002). Comparative analysis of tourist motivations by nationality and destinations. Tourism Management, 23(3), 221-232. doi: https://doi.org/10.1016/ S0261-5177(01)00090-5

Krippendorf, J. (1986). The new tourist-Turning point for leisure and travel. Tourism Management, 7(2), 131-135. doi: https://doi.org/10.1016/0261-5177(86)90025-7

Larsen, S. (2007). Aspects of a psychology of the tourist experience. Scandinavian Journal of Hospitality and Tourism, 7(1), 7-18. doi: 10.1080/15022250701226014

Larson, R. B. (2019). Controlling social desirability bias. International Journal of Market Research, 61(5), 534 537. doi: 10.1177/1470785318805305

Lee, J.-S., Lee, C.-K., \& Choi, Y. (2011). Examining the role of emotional and functional values in festival evaluation. Journal of Travel Research, 50(6), 685-696. doi: $10.1177 / 0047287510385465$

Long, L. M. (2013). Culinary tourism. In P. B. Thompson \& D. M. Kaplan (Eds.), Encyclopedia of food and agricultural ethics (pp. 1-8). Dordrecht, Netherlands: Springer.

Lorentzen, A., \& Hansen, C. J. (2009). The role and transformation of the city in the experience economy: Identifying and exploring research challenges. European Planning Studies, 17(6), 817-827. doi: 10.1080/09654310902793978

Loureiro, S. M. C. (2014). The role of the rural tourism experience economy in place attachment and behavioral intentions. International Journal of Hospitality Management, 40, 1-9. doi: https://doi.org/10.1016/j. ijhm.2014.02.010

Manthiou, A., Lee, S., Tang, L., \& Chiang, L. (2014). The experience economy approach to festival marketing:
Vivid memory and attendee loyalty. Journal of Services Marketing, 28(1), 22-35. doi: 10.1108/JSM-06-20120105

Mason, M. C., \& Paggiaro, A. (2012). Investigating the role of festivalscape in culinary tourism: The case of food and wine events. Tourism Management, 33(6), 1329-1336. doi: https://doi.org/10.1016/j.tourman.2011.12.016

Mathwick, C., Malhotra, N., \& Rigdon, E. (2001). Experiential value: Conceptualization, measurement and application in the catalog and Internet shopping environment. Journal of Retailing, 77(1), 39-56. doi: https://doi. org/10.1016/S0022-4359(00)00045-2

Mehmetoglu, M., \& Engen, M. (2011). Pine and Gilmore's concept of experience economy and its dimensions: An empirical examination in tourism. Journal of Quality Assurance in Hospitality \& Tourism, 12(4), 237-255. doi: 10.1080/1528008X.2011.541847

Mengli, M. (2005). A study on factors affecting consumers' attitude towards online shopping and online shopping intention in Bangkok, Thailand. Retrieved from http:// www4.pucsp.br/icim/ingles/downloads/papers 2010/ part 9/4 A\%20Study\%20on\%20Factors\%20Affecting\%20Consumers Attitude\%20Towards\%20Online.pdf

Mitchell, R., \& Hall, C. M. (2003). Consuming tourists: Food tourism consumer behaviour. In C. M. Hall, L. Sharples, R. Mitchell, N. Macionis, \& B. Cambourne (Eds.), Food tourism around the world (pp. 60-80). Oxford, UK: Routledge.

Morgan, M., Elbe, J., \& de Esteban Curiel, J. (2009). Has the experience economy arrived? The views of destination managers in three visitor-dependent areas. International Journal of Tourism Research, 11(2), 201-216. doi: $10.1002 / \mathrm{jtr} .719$

Moutinho, L. (1987). Consumer behavior in tourism. European Journal of Marketing, 21(10), 5-44.

Namkung, Y., \& Jang, S. (2007). Does food quality really matter in restaurants? its impact on customer satisfaction and behavioral intentions. Journal of Hospitality \& Tourism Research, 31(3), 387-409. doi: 10.1177/1096348007299924

Ohanian, R. (1990). Construction and validation of a scale to measure celebrity endorsers perceived expertise, trustworthiness and attractiveness. Journal of Advertising, 19(3), 39-52.

Oliver, R. L., \& Swan, J. E. (1989). Consumer perceptions of interpersonal equity and satisfaction in transactions: A field survey approach. Journal of Marketing, 53(2), 21-35. doi: 10.2307/1251411

Osmond, A. M., Chen, T., \& Pearce, P. L. (2015). Examining experience economy approaches to tourists' anticipated experiences: Mainland Chinese travellers consider Australia. European Journal of Tourism Research, 10, 95.

Ouellette, J. A., \& Wood, W. (1998). Habit and intention in everyday life: The multiple processes by which past behavior predicts future behavior. Psychological Bulletin, 12(1), 54-74.

Park, S. H., Hsieh, C.-M., \& Lee, C.-K. (2017). Examining Chinese college students' intention to travel to Japan 
using the extended theory of planned behavior: Testing destination image and the mediating role of travel constraints. Journal of Travel \& Tourism Marketing, 34(1), 113-131. doi: 10.1080/10548408.2016.1141154

Parrinello, G. L. (1993). Motivation and anticipation in postindustrial tourism. Annals of Tourism Research, 20(2), 233-249. doi: https://doi.org/10.1016/0160-7383(93)90 052-5

Pearce, P. L. (1982). The social psychology of tourist behaviour. Oxford, UK: Pergamon Press.

Pearce, P. L. (1988). The Ulysses factor: Evaluating visitors in tourist settings. New York, NY: Springer-Verlag.

Pearce, P. L., \& Lee, U.-I. (2005). Developing the travel career approach to tourist motivation. Journal of Travel Research, 43(3), 226-237. doi: 10.1177/0047287504272020

Petkus Jr., E. (2004). Enhancing the application of experiential marketing in the arts. International Journal of Nonprofit and Voluntary Sector Marketing, 9(1), 49-56. doi: $10.1002 /$ nvsm. 232

Pine, B. J., \& Gilmore, J. H. (1999). The experience economy. Cambridge, MA: Harvard University Press.

Plog, S. C. (2002). The power of psychographics and the concept of venturesomeness. Journal of Travel Research, 40(3), 244-251. doi: 10.1177/004728750204000302

Promsivapallop, P., \& Kannaovakun, P. (2019). Destination food image dimensions and their effects on food preference and consumption. Journal of Destination Marketing \& Management, 11, 89-100. doi: https://doi. org/10.1016/j.jdmm.2018.12.003

Quadri-Felitti, D., \& Fiore, A. M. (2012). Experience economy constructs as a framework for understanding wine tourism. Journal of Vacation Marketing, 18(1), 3-15. doi: $10.1177 / 1356766711432222$

Quan, S., \& Wang, N. (2004). Towards a structural model of the tourist experience: An illustration from food experiences in tourism. Tourism Management, 25(3), 297-305.

Richards, G. (2015). Evolving gastronomic experiences: From food to foodies to foodscapes. Journal of Gastronomy and Tourism, 1(1), 5-17.

Richards, G. (2018). Cultural tourism: A review of recent research and trends. Journal of Hospitality and Tourism Management, 36, 12-21. doi: https://doi.org/10.1016/j. jhtm.2018.03.005

Ritchie, J. R. B., \& Hudson, S. (2009). Understanding and meeting the challenges of consumer/tourist experience research. International Journal of Tourism Research, 11(2), 111-126. doi: 10.1002/jtr.721

Ross, G. F. (1993). Tourist motivation among backpacker visitors to the wet tropics of Northern Australia. Journal of Travel \& Tourism Marketing, 1(3), 43-60. doi: 10.1300/J073v01n03 03

Sánchez-Cañizares, S. M.̄., \& López-Guzmán, T. (2012). Gastronomy as a tourism resource: Profile of the culinary tourist. Current Issues in Tourism, 15(3), 229-245. doi: 10.1080/13683500.2011.589895

Serra, J., Correia, A., \& Rodrigues, P. M. M. (2014). A comparative analysis of tourism destination demand in Portugal. Journal of Destination Marketing \& Management, 2(4), 221-227. doi: https://doi.org/10.1016/j. jdmm.2013.10.002

Sharples, L. (2003). The world of cookery-school holidays. In C. M. Hall, L. Sharples, R. Mitchell, N. Macionis, \& B. Cambourne (Eds.), Food tourism around the world (pp. 102-120). Oxford, UK: Routledge.

Sidali, K. L., Kastenholz, E., \& Bianchi, R. (2015). Food tourism, niche markets and products in rural tourism: Combining the intimacy model and the experience economy as a rural development strategy. Journal of Sustainable Tourism, 23(8-9), 1179-1197. doi: $10.1080 / 09669582.2013 .836210$

Sims, R. (2009). Food, place and authenticity: Local food and the sustainable tourism experience. Journal of Sustainable Tourism, 17(3), 321-336.

Smith, S., \& Costello, C. (2009). Culinary tourism: Satisfaction with a culinary event utilizing importanceperformance grid analysis. Journal of Vacation Marketing, 15(2), 99-110.

Smith, S. L. J., \& Xiao, H. (2008). Culinary tourism supply chains: A preliminary examination. Journal of Travel Research, 46(3), 289-299. doi: 10.1177/ 0047287506303981

Song, H., van der Veen, R., Li, G., \& Chen, J. L. (2012). The Hong Kong tourist satisfaction index. Annals of Tourism Research, 39(1), 459-479. doi: https://doi.org/10.1016/j. annals.2011.06.001

Song, H. J., Lee, C.-K., Park, J. A., Hwang, Y. H., \& Reisinger, Y. (2015). The influence of tourist experience on perceived value and satisfaction with temple stays: The experience economy theory. Journal of Travel \& Tourism Marketing, 32(4), 401-415. doi: 10.1080/10548408.2014.898606

Soonsap, P. (2018, January 19-20). Understanding international tourists' perspective on slow food tourism's current market in Chiang Mai, Thailand. Paper presented at the ICT18 Hong Kong Conference. Proceedings of the International Conference on Tourism \& Marketing Hong Kong.

Sosik, J. J., Kahai, S. S., \& Piovoso, M. J. (2009). Silver bullet or voodoo statistics?: A primer for using the partial least squares data analytic technique in group and organization research. Group \& Organization Management, 34(1), 5-36. doi: 10.1177/1059601108329198

Spence, F., \& Van Teijlingen, E. R. (2005). A qualitative evaluation of community-based cooking classes in Northeast Scotland. International Journal of Health Promotion and Education, 43(2), 59-63.

Suntikul, W., \& Jachna, T. (2016). The co-creation/place attachment nexus. Tourism Management, 52, 276-286. doi: https://doi.org/10.1016/j.tourman.2015.06.026

Tabassi, A. A., \& Bakar, A. H. A. (2009). Training, motivation, and performance: The case of human resource management in construction projects in Mashhad, Iran. International Journal of Project Management, 27(5), 471-480. doi: https://doi.org/10.1016/j.ijproman. 2008.08.002 
Tikkanen, I. (2007). Maslow's hierarchy and food tourism in Finland: Five cases. British Food Journal, 109(9), 721-734. doi: 10.1108/00070700710780698

Tolkach, D., Chon, K. K. S., \& Xiao, H. (2016). Asia Pacific tourism trends: Is the future ours to see? Asia Pacific Journal of Tourism Research, 21(10), 1071-1084. doi: 10.1080/10941665.2015.1118395

Tourism Authority of Thailand. (2013). Chiang Mai. Retrieved from https://www.tourismthailand.org/AboutThailand/Destination/Chiang-Mai

TripAdvisor. (2018). Top cooking classes in Chiang Mai, Thailand. Retrieved from https://www.tripadvisor.com/ Attractions-g293917-Activities-c36-t203-Chiang_Mai. html

Tsai, C.-T., \& Wang, Y.-C. (2017). Experiential value in branding food tourism. Journal of Destination Marketing \& Management, 6(1), 56-65. doi: https://doi. org/10.1016/j.jdmm.2016.02.003

Volo, S. (2013). Conceptualizing experience: A tourist based approach. In N. Scott, E. Laws, \& P. Boksberger (Eds.), Marketing of tourism experiences (pp. 19-34). London, UK: Routledge.

Waller, J., \& Lea, S. E. G. (1999). Seeking the real spain? Authenticity in motivation. Annals of Tourism Research, 26(1), 110-129. doi: https://doi.org/10.1016/S01607383(98)00058-9

Walter, P. (2017). Culinary tourism as living history: Staging, tourist performance and perceptions of authenticity in a Thai cooking school. Journal of Heritage Tourism, 12(4), 365-379. doi: 10.1080/1743873X.2016.1207651

Whang, H., Yong, S., \& Ko, E. (2016). Pop culture, destination images, and visit intentions: Theory and research on travel motivations of Chinese and Russian tourists.
Journal of Business Research, 69(2), 631-641. doi: https://doi.org/10.1016/j.jbusres.2015.06.020

Williams, A. (2006). Tourism and hospitality marketing: Fantasy, feeling and fun. International Journal of Contemporary Hospitality Management, 18(6), 482-495.

Witt, C. A., \& Wright, P. L. (1992). Tourist motivation: Life after Maslow. In P. Johnson \& B. Thomas (Eds.), Choice and demand in tourism (pp. 33-35). London, UK: Mansell Publishing.

Wu, H.-C., Wong, J. W.-C., \& Cheng, C.-C. (2014). An empirical study of behavioral intentions in the food festival: The case of Macau. Asia Pacific Journal of Tourism Research, 19(11), 1278-1305.

Wu, M.-Y., \& Pearce, P. L. (2014). Chinese recreational vehicle users in Australia: A netnographic study of tourist motivation. Tourism Management, 43, 22-35. doi: http://dx.doi.org/10.1016/j.tourman.2014.01.010

Yoon, Y., \& Uysal, M. (2005). An examination of the effects of motivation and satisfaction on destination loyalty: A structural model. Tourism Management, 26(1), 45-56.

Yu, C.-C. (2010). Factors that influence international fans' intention to travel to the United States for sport tourism. Journal of Sport \& Tourism, 15(2), 111-137. doi: $10.1080 / 14775085.2010 .498249$

Yuan, J., Morrison, A. M., Cai, L. A., \& Linton, S. (2008). A model of wine tourist behaviour: A festival approach. International Journal of Tourism Research, 10(3), 207-219. doi: 10.1002/jtr.651

Zeithaml, V. A. (1988). Consumer perceptions of price, quality, and value: A means-end model and synthesis of evidence. Journal of Marketing, 52(3), 2-22. doi: $10.1177 / 002224298805200302$ 